\title{
The effects of adding fat to diets of lactating dairy cows on total-tract neutral detergent fiber digestibility: A meta-analysis
}

\author{
K. A. Weld and L. E. Armentano ${ }^{1}$ \\ Department of Dairy Science, University of Wisconsin-Madison, Madison 53706
}

\begin{abstract}
The objective of this meta-analysis was to determine the effects of supplemental fat on fiber digestibility in lactating dairy cattle. Published papers that evaluated the effects of adding fat to the diets of lactating dairy cattle on total-tract neutral detergent fiber digestibility (ttNDFd) and dry matter intake (DMI) were compiled. The final data set included 108 fat-supplemented treatment means, not including low-fat controls, from 38 publications. The fat-supplemented treatment means exhibited a wide range of ttNDFd $(49.4 \% \pm 9.3$, mean \pm standard deviation $)$ and DMI $(21.3 \mathrm{~kg} / \mathrm{d} \pm 3.5)$. Observations were summarized as the difference between the treatment means for fat-supplemented diets minus their respective low-fat control means. Additionally, those differences were divided by the difference in diet fatty acid (FA) concentration between the treatment and control diets. Treatment means were categorized by the type of fat supplement. Supplementing 3\% FA in the diet as medium-chain fats (containing predominately 12- and 14-carbon saturated FA) or unsaturated vegetable oil decreased ttNDFd by 8.0 and 1.2 percentage units, respectively. Adding $3 \%$ calcium salts of long-chain FA or saturated fats increased ttNDFd by 3.2 and 1.3 percentage units, respectively. No other fat supplement type affected ttNDFd. Except for saturated fats and animal-vegetable fats, supplementing dietary fat decreased DMI. When the values for changes in ttNDFd are regressed on changes in DMI there was a positive relationship, though the coefficient of determination is only 0.20 . When changes in ttNDFd were regressed on changes in DMI, within individual fat supplement types, there was no relationship within calcium salt supplements. There was a positive relationship between changes in ttNDFd and changes in DMI for saturated fats. Neither relationship suggested that the increased ttNDFd with calcium salts or saturated FA was due to decreased DMI for these fat sources. A
\end{abstract}

Received May 23, 2016.

Accepted October 31, 2016.

${ }^{1}$ Corresponding author: learment@wisc.edu subset of the means included measured ruminal neutral detergent fiber digestion. Analysis of this smaller data set did not suggest that ruminal neutral detergent fiber digestibility is depressed by fat supplementation more than ttNDFd. Adding fats, other than those with medium-chain FA, consistently increased digestible energy density of the diet. However, due to reduced DMI, this increased energy density may not result in increased digestible nutrient intake.

Key words: NDF digestibility, dietary fat, DMI, dairy cow

\section{INTRODUCTION}

The NRC (2001) and literature reviews (Palmquist and Jenkins, 1980; Jenkins, 1993) cite dietary fat as having a negative effect on fiber digestibility in lactating dairy cattle. This conclusion is primarily based on evidence showing that fat decreases NDF digestibility in steers and sheep (Ward et al., 1957; Devendra and Lewis, 1974; Jenkins and Palmquist, 1984). Overall, evidence is lacking that the same decrease in fiber digestibility occurs in lactating dairy cattle when fat is supplemented (Palmquist, 1991; Brask et al., 2013). Some studies have found that fat significantly decreased total-tract NDF digestibility (ttNDFd) in lactating dairy cattle, but the magnitude of the decrease was minimal (Ueda et al., 2003; Martin et al., 2008; Reveneau et al., 2012). A published summary of the effect of fat addition on fiber digestion in lactating dairy cows is not available.

The NRC (2001) cites unsaturated fats as having a more negative effect on rumen fermentation compared with calcium salts and hydrogenated fats. This is attributed to possible differences in the effects on microbial populations as it is known that UFA can affect microbial growth rates in vitro (Maia et al., 2007). Additionally, increasing the particle size of the fats or oilseeds is recognized as a possible mechanism for decreasing negative effects of UFA (Weld and Armentano, 2016). The presence of additional dietary calcium or fat in the form of calcium salts, rather than fatty acids (FA), has been shown to reverse negative effects of fat 
on fiber digestibility (Ward et al., 1957; White et al., 1958; Jenkins and Palmquist, 1984).

The objective of this meta-analysis is to provide a quantitative summary of the effects of fat supplementation on ttNDFd in lactating dairy cattle reported in the literature. Despite the presence of reviews on the effects of fat on ruminal fermentation, they do not offer a quantitative summary or analysis of the effects of fat on fiber digestibility. As the complexity of nutrient requirement models intensifies, a quantitative understanding of the effects of fat supplementation to the diets of high-producing dairy cattle will be necessary.

\section{MATERIALS AND METHODS}

\section{Study Selection}

Papers published in English between 1980 and 2015 that reported ttNDFd in lactating dairy cattle fed fat-supplemented diets and a corresponding lower-fat control diet were compiled using Google Scholar, Web of Knowledge, and the Journal of Dairy Science as search engines. Combinations of the following search terms were used: fat, fatty acid, fiber digest, dairy, cow, oil, tallow, Ca salts, hydrogenated, saturated, canola, flaxseed, linseed, sunflower, soybean, and rapeseed. Relevant citations from these papers were included as well.

Treatments included in the final analysis reported ttNDFd and dietary FA or ether extract $(\mathbf{E E})$; had a corresponding low-fat control diet with a similar forageto-concentrate ratio as the treatment $\operatorname{diet}(\mathrm{s})$ (within 5 percentage points); used lactating dairy cows; and supplemented fat orally. We excluded studies supplementing fat in the form of full-fat oilseeds of any particle size due to the possible confounding effect of altering the source of NDF in the diet and oil availability.

We formed supplemental fat categories based on the descriptions and FA compositions of fat supplements reported in the studies, which resulted in some variation of FA composition within categories (Table 1). Calcium salts of palm oil were categorized separate from calcium salts of long-chain FA (LCFA) because of the differing FA profile. Oils and calcium salts of LCFA include all seed oils, but not palm oil. Oleamide treatments were included in the analysis for the purpose of study effects, but the results are not reported because there were only 2 treatments. One publication did not report the standard error (SE) of ttNDFd, so SE was calculated using the mean square error reported (Smith et al., 1993).

\section{Statistics}

Many studies fed more than 1 fat type at similar dietary concentrations with a shared lower-fat control diet, whereas relatively few studies examined multiple levels of the same fat type (Figure 1). For all studies, each fat treatment mean and its corresponding control mean within a study were summarized into 1 observa-

Table 1. Description of the fat treatment means included in the data set

\begin{tabular}{lccccc}
\hline Variable & Mean & SD & Minimum & Maximum & $\mathrm{n}^{2}$ \\
\hline ttNDFd $^{1}$ (\%) & 49.4 & 9.3 & 28.8 & 66.8 & 98 \\
DMI (kg/d) $_{\text {Acetate:propionate ratio }}$ & 21.3 & 3.5 & 13.4 & 27.8 & 93 \\
Diet characteristics (\% of DM) & 2.73 & 0.45 & 1.46 & 3.61 & 63 \\
Fatty acids & & & & & \\
$\Delta$ FA $^{3}$ & 6.2 & 1.3 & 3.8 & 10.0 & 98 \\
NDF & 3.3 & 1.3 & 1.1 & 6.6 & 98 \\
CP & 32.4 & 4.3 & 22.5 & 43.3 & 98 \\
NFC & 17.1 & 1.3 & 14.1 & 20.8 & 98 \\
Calcium & 36.2 & 4.9 & 22.6 & 48.9 & 98 \\
Forage level & 1.0 & 0.2 & 0.5 & 1.3 & 47 \\
Production parameters & 49.6 & 7.7 & 35.0 & 67.0 & 98 \\
Milk (kg/d) & & & & & \\
Fat (\%) & 32.3 & 7.5 & 14.1 & 57.7 & 89 \\
Protein (\%) & 3.36 & 0.47 & 2.37 & 4.67 & 89 \\
DIM & 3.07 & 0.19 & 2.71 & 3.54 & 87 \\
Total-tract apparent digestibility (\%) & 101 & 52 & 31 & 213 & 82 \\
Fatty acids & & & & & \\
Ether extract & 67.3 & 11.3 & 36.7 & 92.7 & 56 \\
OM & 77.6 & 9.8 & 59.6 & 93.0 & 32 \\
P & 67.4 & 4.7 & 54.1 & 77.1 & 75 \\
\hline
\end{tabular}

${ }^{1}$ ttNDFd $=$ total-tract NDF digestibility.

${ }^{2} \mathrm{n}=$ number of fat treatments.

${ }^{3} \Delta \mathrm{FA}=$ change in dietary fatty acid concentration from the lower fat control. 


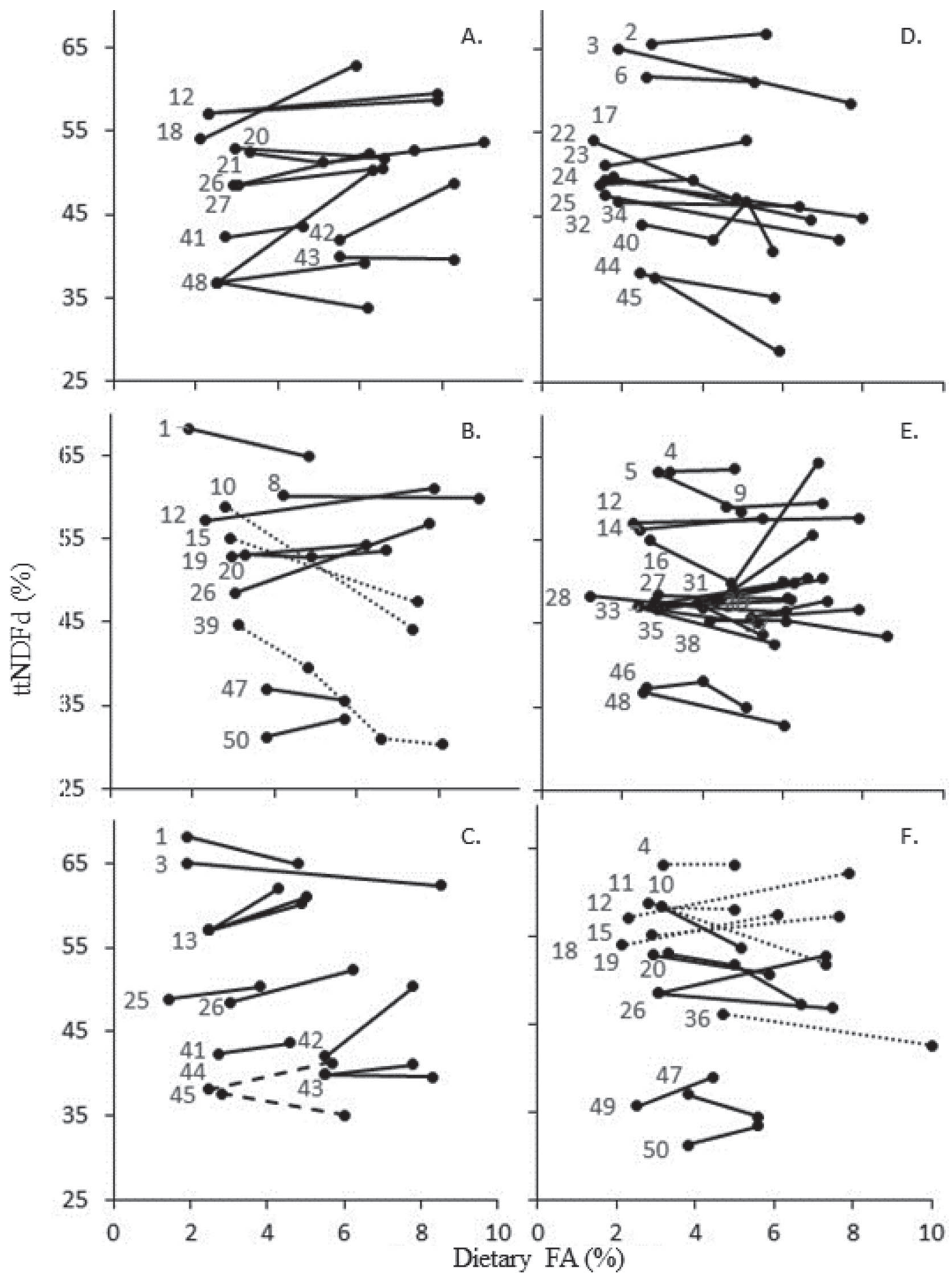

Figure 1. Total-tract NDF digestibility (ttNDFd) versus dietary fatty acid (FA) content (\% DM). (A) Saturated fat; (B) calcium salts of palm oil (solid line), medium-chain FA (dotted line); (C) calcium salts of long-chain FA, oils (solid lines), oleamides (dashed lines); (D) oil; (E) tallow; (F) animal-vegetable fat (dotted line), C16 (solid line). Lines connect data points of treatment within a study. Fat types within a study generally share the same low-fat control. Numbers correspond to a low-fat control (Table 2) and are numbered in order from the greatest ttNDFd to the least ttNDFd.

tion, calculated as the ttNDFd treatment mean minus the ttNDFd mean of the control diet $(\Delta \mathrm{ttNDFd})$, with a similar calculated mean difference for DMI $(\Delta \mathrm{DMI})$.
For studies that reported EE rather than FA content of the diet, 1 percentage unit was subtracted from the EE to estimate FA (NRC, 2001). This should have 
minimal effect on the difference in FA content between control and treatment diets (added FA, $\boldsymbol{\Delta}$ FA), but could have had a larger effect on FA concentration if absolute concentrations were used across studies in a linear regression approach. Studies were weighted by the inverse of the SE of ttNDFd for both ttNDFd and DMI analysis.

The $\triangle \mathrm{DMI}$ and $\Delta \mathrm{ttNDFd}$ were divided by $\Delta \mathrm{FA}$ to give a change in ttNDFd $(\Delta$ ttNDFd/1\%FA) or DMI $(\Delta \mathrm{DMI} / \mathbf{1 \%} \mathbf{F A})$ per 1-percentage-unit increase in dietary FA. The assumption of a linear effect of fat on ttNDFd and DMI was made; this was validated by examining the effect of $\triangle \mathrm{FA}$ on $\triangle \mathrm{ttNDFd}$ and $\triangle \mathrm{DMI}$.

Analysis was conducted using SAS 9.4 (SAS Institute Inc., Cary, NC). Significant effects for each model were determined using the MIXED procedure by manual stepwise deletion. Independent variables eligible for inclusion were (expressed as percent of diet DM unless otherwise noted) forage level, corn silage level, NDF, $\mathrm{CP}, \mathrm{NFC}, \mathrm{FA}, \triangle \mathrm{FA}$, and proportion of corn silage (percent of forage level). All independent variables were corrected by subtracting the mean value of all studies so that they were distributed around zero, as the intercept of the model was forced through zero.

The first model was a regression of $\triangle$ ttNDFd on $\Delta$ FA. Fat supplementation must have been of only 1 type (for example oil or C16, but not both). The intercepts for all fat types were forced through zero, which represents no fat addition or control. The model was

$$
Y_{i j}=B_{i} X_{i}+C_{j} Z_{j}+s_{j}+e_{i j} \text {, }
$$

where $Y_{i j}$ is the $\Delta$ ttNDFd of the jth study within the ith fat type; $\mathrm{B}_{\mathrm{i}} \mathrm{X}_{\mathrm{i}}$ is the slope of the ith fat supplement due to $\triangle \mathrm{FA} ; \mathrm{C}_{\mathrm{j}} \mathrm{Z}_{\mathrm{j}}$ is the effect of dietary parameter; $\mathrm{s}_{\mathrm{j}}$ is the random effect of the jth study; and $\mathrm{e}_{\mathrm{ij}}$ is the residual error. The slope of each fat type $\left(\mathrm{B}_{\mathrm{i}}\right)$ was tested to determine if it was different from zero. No dietary parameters besides $\mathrm{CP}$ were significant in the final model. The quadratic effect of $\Delta \mathrm{FA}$ was tested and not found to be significant.

The second model determined the least squares means for $\Delta$ ttNDFd/1\%FA. Fat supplementation again must have been only of 1 type. The MIXED procedure was used with the model

$$
\mathrm{Y}_{\mathrm{ij}}=\mu+\mathrm{B}_{\mathrm{i}}+\mathrm{s}_{\mathrm{j}}+\mathrm{e}_{\mathrm{ij}},
$$

where $\mathrm{Y}_{\mathrm{ij}}$ is the $\Delta \mathrm{ttNDFd} / 1 \% \mathrm{FA}$ of the jth study within the ith fat type; $\mu$ is the overall mean; $B_{i}$ is the effect of the ith fat type; $s_{j}$ is the random effect of study and $e_{i j}$ is the residual error. Least squares means were determined and the Bonferroni adjustment was used to determine which means were significantly different.

The same models were used for DMI, weighted by the SE of ttNDFd, with the exception that the first model did not include the effects of dietary $\mathrm{CP}$ on $\triangle \mathrm{DMI}$.

The REG procedure was used to determine if there was a significant relationship between $\Delta$ ttNDFd and $\Delta$ DMI. Treatments with multiple sources contributing to fat supplementation were included in addition to those with a single source. Least squares means and slopes were tested to determine if they were significantly different from zero (null hypothesis: fat addition has no effect). Significance was declared for $P \leq 0.05$ and a tendency was declared for $0.05<P \leq 0.10$.

\section{TDN Calculations}

Predicted changes in TDN concentration and intake due to supplementation of each fat type were modeled using the least squares means of $\Delta \mathrm{DMI} / 1 \% \mathrm{FA}$ and $\Delta \mathrm{ttNDFd} / 1 \% \mathrm{FA}$. A low-fat control diet was designed that contained $43 \%$ NFC, $30 \%$ NDF, $17 \%$ CP, $2 \%$ FA, and $8 \%$ ash on a DM basis. The total-tract digestibility of nutrients were assigned to be $75 \%$ for FA (Boerman et al., 2015), 65\% for CP (Lapierre et al., 2005), and $80 \%$ for NFC (calculated based on other digestibilities), and were not changed with fat supplementation. The control diet was assigned the mean ttNDFd and DMI (49.6\% and $22.4 \mathrm{~kg} / \mathrm{d}$, respectively) from the controls of the studies compiled. The fat-supplemented diets were simulated by substituting 3\% FA for 3\% NFC. The digestibility of fat from different sources was not an objective of this review, and fat digestibility of $75 \%$ was not changed depending on the type of fat supplemented; therefore, these estimated changes in TDN will undervalue more digestible fat sources and over value poorly digested fat sources. Dry matter intake and ttNDFd were the only values changed for different fat supplement types.

\section{RESULTS AND DISCUSSION}

\section{Data}

The compiled studies represent a large range of production parameters and digestibilities (Tables 1 and 2 , Figure 1). Some of the numerical differences may be attributed to the large range of average DIM and the range of time over which studies were published (1987-2015). Some of the numerical differences in ttNDFd among studies are likely due to variations in methodology, which have been shown to affect estimates of digestibility (Harvatine and Allen, 2006; Lee 
Table 2. Citations of studies included in the data set with the corresponding ranking of the total-tract NDF digestibility (ttNDFd) of the control (Figure 1) and a description of the treatments

\begin{tabular}{|c|c|c|}
\hline Citation & $\operatorname{Rank}^{1}$ & Fat types $(\mathrm{L})^{2}$ \\
\hline Enjalbert et al. (1997) & 1 & CSLCFA (1), CSP (1) \\
\hline Benchaar et al. (2015) & 2,17 & Oil (2) \\
\hline Doreau et al. $(1993)^{3}$ & 3 & CSLCFA (1), Oil (1) \\
\hline Avila et al. $(2000)^{3}$ & 4 & AV (1), Tal (1) \\
\hline Smith et al. (1993) & $5,9,14,16,29,30$ & Tal (6) \\
\hline Brask et al. $(2013)^{3}$ & 6 & Oil (1) \\
\hline Ueda et al. $(2003)^{3}$ & 7,22 & Oil (2) \\
\hline Aldrich et al. (1997) & 8 & $\operatorname{CSP}(1)$ \\
\hline Reveneau et al. $(2012)^{3}$ & 10,15 & $\operatorname{AV}(2), \operatorname{MCFA}(2)$ \\
\hline Kargar et al. (2012) & 11 & $\mathrm{AV}(1), \mathrm{C} 16(1)$ \\
\hline Palmquist (1991) & 12 & $\operatorname{AV}(1), \operatorname{CSP}(1)$, Tal (1), Sat (2) \\
\hline Chouinard et al. (1998) & 13 & CSLCFA (3) \\
\hline Pantoja et al. $(1994)^{3}$ & 18 & AV (1), Sat (1) \\
\hline Weiss and Wyatt (2004) & 19 & $\operatorname{CSP}(2), \mathrm{C} 16(2)$ \\
\hline Weiss et al. (2011) & 20 & CSP (1), C16 (1), Sat (1) \\
\hline Drackley and Elliott (1993) & 21 & Sat (3) \\
\hline Do Prado et al. (2015) & 23,34 & Oil (2) \\
\hline Chelikani et al. $(2004)^{3}$ & 24 & Oil (1) \\
\hline Freitas et al. (2014) & 25 & Oil (1),CSP (1) \\
\hline Elliott et al. (1996) & 26 & C16 (2), Sat (1), CSP (1) \\
\hline Pantoja et al. (1996) & 27 & Tal (1), Sat (1) \\
\hline DePeters et al. (1987) & 28 & $\mathrm{Tal}(2)$ \\
\hline Ruppert et al. (2003) & 31,46 & Tal (4) \\
\hline Martin et al. (2008) & 32 & Oil (1) \\
\hline Weigel et al. (1997) & 33 & Tal (4) \\
\hline Drackley et al. (1994) & 35 & Tal (3) \\
\hline Hollmann and Beede (2012) & 36 & AV (1) \\
\hline Schauff et al. (1992) & 37 & Tal (2) \\
\hline Elliott et al. (1994) & 38 & Tal (2) \\
\hline Faciola and Broderick (2013) & 39 & MCFA (3) \\
\hline Benchaar et al. (2012) & 40 & Oil (3) \\
\hline Piantoni et al. (2015) & 41 & Sat (1) \\
\hline Harvatine and Allen $(2006)^{3}$ & 42,43 & CSLCFA (2), Sat (2) \\
\hline Jenkins (1998) & 44 & Oil (1), Oleamide (1) \\
\hline Deluca and Jenkins (2000) & 45 & Oil (1), Oleamide (1) \\
\hline Rico et al. (2014) & 47,50 & CSP (2), C16 (2) \\
\hline Eastridge and Firkins (2000) & 48 & Tal (1), Sat (3) \\
\hline Piantoni et al. (2013) & 49 & C16 (1) \\
\hline \multicolumn{3}{|c|}{$\begin{array}{l}{ }^{1} \text { Multiple rank numbers indicate multiple control treatments differing in forage level, forage type or protein } \\
\text { level. } \\
{ }^{2} \mathrm{AV}=\text { animal-vegetable fat; Sat = saturated fat; } \mathrm{CSP}=\text { calcium salts of palm; CSLCFA = calcium salts of } \\
\text { long-chain fatty acid; MCFA = medium-chain fatty acid (C12 and C14); Tal = tallow; L is the number of } \\
\text { dietary levels of that particular fat supplement. }\end{array}$} \\
\hline
\end{tabular}

and Hristov, 2014). This should not have significantly affected our data due to the inclusion of random study effects and the analysis of differences between the control and treatment.

There were numerical differences in the mean of the dietary FA concentrations of the controls and the differences between the controls and treatments across studies and fat types (Table 3), but these were accounted for by the analysis of the data as slopes. There were also numerical differences in the means of the controls of ttNDFd and DMI among fat types (Table 4), but these differences were assumed to have little impact on the effect of fat supplementation on ttNDFd or DMI.

Most of the fat categories were fairly uniform in FA profile. However, the C16 category contained fat supple- ments with proportions of C16 ranging from 49 to $99 \%$ $(67.8 \pm 17.8$, mean $\pm \mathrm{SD})$ of total FA, and the oils and calcium salts of LCFA contained a variety of 18-carbon FA unsaturation levels. There are only 3 fat categories that had both FA and triglycerides (TG) within them: saturated fats, medium-chain FA (MCFA; 12- and 14-carbon FA), and C16. None had many FA treatments compared with the number of TG treatments. Therefore, we drew no conclusions about the differing effects of dietary TG versus FA based on the data, but it is an area that should be investigated further. This may be an important distinction, as calcium salts are a nonesterified FA, but are often compared with TG of similar FA profile rather than to FA. Jenkins and Palmquist (1984) showed that FA have more negative 
Table 3. Raw means of dietary fatty acid (FA) concentration of treatment and control diets and the primary and secondary $\left(1^{\circ}\right.$ and $\left.2^{\circ}\right)$ FA present in each supplement

\begin{tabular}{|c|c|c|c|c|c|c|c|c|}
\hline \multirow[b]{2}{*}{ Fat supplement type } & \multicolumn{2}{|c|}{$\mathrm{N}^{1}$} & \multicolumn{3}{|c|}{ Diet FA $(\%$ DM, mean \pm SD $)$} & \multirow{2}{*}{$\begin{array}{c}\Delta \mathrm{FA}+\mathrm{NFC}^{2} \\
(\% \mathrm{DM})\end{array}$} & \multicolumn{2}{|c|}{ FA profile } \\
\hline & Trt & Pub & Control & Treatment & $\Delta \mathrm{FA}$ & & $1^{\circ} \mathrm{FA}$ & $2^{\circ} \mathrm{FA}$ \\
\hline $\mathrm{MCFA}^{3}$ & 5 & 2 & $3.0 \pm 0.1$ & $6.9 \pm 1.3$ & $3.9 \pm 1.3$ & $2.0 \pm 2.0$ & $12: 0$ & 14:0 \\
\hline Oil & 16 & 11 & $2.1 \pm 0.5$ & $5.8 \pm 1.2$ & $3.7 \pm 1.4$ & $2.4 \pm 3.0$ & $18: 3$ & $18: 1$ \\
\hline C16 & 9 & 4 & $3.2 \pm 0.4$ & $5.9 \pm 1.0$ & $2.7 \pm 1.1$ & $1.4 \pm 1.5$ & $16: 0$ & $18: 1$ \\
\hline Animal-vegetable & 7 & 6 & $3.0 \pm 0.8$ & $7.0 \pm 1.8$ & $4.0 \pm 1.6$ & $0.7 \pm 0.9$ & $18: 1$ & $18: 2$ \\
\hline Tallow & 27 & 11 & $3.1 \pm 1.0$ & $6.0 \pm 1.2$ & $3.1 \pm 1.2$ & $0.9 \pm 2.1$ & $18: 1$ & $16: 0$ \\
\hline Saturated fat & 15 & 8 & $3.1 \pm 1.0$ & $6.8 \pm 1.3$ & $3.7 \pm 1.2$ & $0.4 \pm 2.5$ & 18:0 & $16: 0$ \\
\hline Overall mean ${ }^{5}$ & 98 & 38 & $2.9 \pm 1.0$ & $6.2 \pm 1.3$ & $3.3 \pm 1.3$ & $0.8 \pm 1.7$ & - & - \\
\hline
\end{tabular}

${ }^{1}$ Trt $=$ treatment means; Pub = publications.

${ }^{2} \Delta \mathrm{FA}+\mathrm{NFC}=$ change in the sum of NFC and FA fractions (treatment - control).

${ }^{3} \mathrm{MCFA}=$ medium-chain $\mathrm{FA}, \mathrm{C} 12$ and $\mathrm{C} 14$.

${ }^{4} \mathrm{LCFA}=$ long-chain FA.

${ }^{5}$ Includes the oleamide treatments $(\mathrm{n}=2)$.

effects on total-tract ADF digestibility compared with calcium salts of the same FA profile. These data should be applied to current ttNDFd cautiously due to differences between ADF and NDF digestibility, as well as the low production $(18.3 \mathrm{~kg} / \mathrm{d})$, in the 1984 study.

Prior to classification of fat supplementation and summary of the treatment means as differences from the controls, an attempt was made to do the analysis as described by St. Pierre (2001) using the dietary FA (\% $\mathrm{DM}$ ) of the control and treatment diets. However, due to the differing effects of types of fat and the limited range over which FA are supplemented, no additional useful information was gained from consolidating the effects of fat into one linear model. Additionally, the attempt was made to analyze the data using the relative concentrations of specific FA in the supplements or diets. However, the number of studies reporting the necessary information was minimal. Therefore, the decision was made to determine the effects for specific categories of fat supplements. The addition of published literature containing FA profiles of the diet would be beneficial in further evaluating the effects of specific FA on NDF digestibility.

\section{Total-Tract NDF Digestibility}

Change in FA within type of fat was significant as a linear effect in the model for $\Delta$ ttNDFd $(P<0.05)$. Total FA content of the treatment diet did not provide a better model fit than $\triangle \mathrm{FA}$, and $\triangle \mathrm{FA}$ as a quadratic effect was not significant $(P>0.10)$. Medium-chain FA and oil both significantly decreased ttNDFd, though the magnitude of the decrease in ttNDFd was much less for oil (0.6 percentage units/1\% FA) than that for MCFA (2.7 percentage units/1\% FA; Table 5, Figure $2)$. Saturated fats tended to increase ttNDFd (0.4 per-

Table 4. Unweighted means of total-tract NDF digestibility (ttNDFd) and DMI by fat supplement type

\begin{tabular}{|c|c|c|c|c|c|c|c|c|}
\hline Fat supplement type & \multicolumn{4}{|c|}{$\operatorname{ttNDFd}(\%$, mean $\pm \mathrm{SD})$} & \multicolumn{4}{|c|}{ DMI $(\mathrm{kg} / \mathrm{d}$, mean $\pm \mathrm{SD})$} \\
\hline $\mathrm{MCFA}^{2}$ & 5 & $49.5 \pm 6.9$ & $38.5 \pm 7.7$ & -11.0 & 5 & $22.5 \pm 2.6$ & $18.5 \pm 3.4$ & -4.0 \\
\hline Oil & 16 & $50.5 \pm 8.8$ & $48.2 \pm 10.3$ & -2.3 & 16 & $19.4 \pm 2.9$ & $18.4 \pm 2.7$ & -1.0 \\
\hline C16 & 9 & $46.5 \pm 9.5$ & $45.5 \pm 7.9$ & -1.0 & 9 & $24.5 \pm 2.6$ & $24.1 \pm 2.3$ & -0.4 \\
\hline Animal-vegetable & 7 & $56.1 \pm 5.3$ & $56.1 \pm 7.0$ & 0.0 & 6 & $22.8 \pm 3.5$ & $22.0 \pm 3.5$ & -0.8 \\
\hline Tallow & 27 & $48.6 \pm 6.7$ & $49.0 \pm 7.8$ & +0.4 & 26 & $23.1 \pm 3.2$ & $22.2 \pm 3.1$ & -0.9 \\
\hline Saturated fat & 15 & $47.3 \pm 7.5$ & $49.9 \pm 8.0$ & +2.6 & 13 & $23.3 \pm 2.3$ & $23.4 \pm 2.1$ & 0.1 \\
\hline Overall mean & 96 & $49.6 \pm 8.4$ & $49.4 \pm 9.3$ & -0.2 & 91 & $22.4 \pm 3.4$ & $21.3 \pm 3.5$ & -1.1 \\
\hline
\end{tabular}

${ }^{1}$ Control is weighted by the number of fat treatments from each publication; $\Delta=$ treatment - control.

${ }^{2} \mathrm{MCFA}=$ medium-chain fatty acid, $\mathrm{C} 12$ and $\mathrm{C} 14$.

${ }^{3} \mathrm{LCFA}=$ long-chain fatty acid. 
Table 5. Changes in total-tract NDF digestibility $(\Delta \mathrm{ttNDFd})$ and change in DMI $(\Delta \mathrm{DMI})$ when fat is supplemented to a lower fat control diet based on a regression model

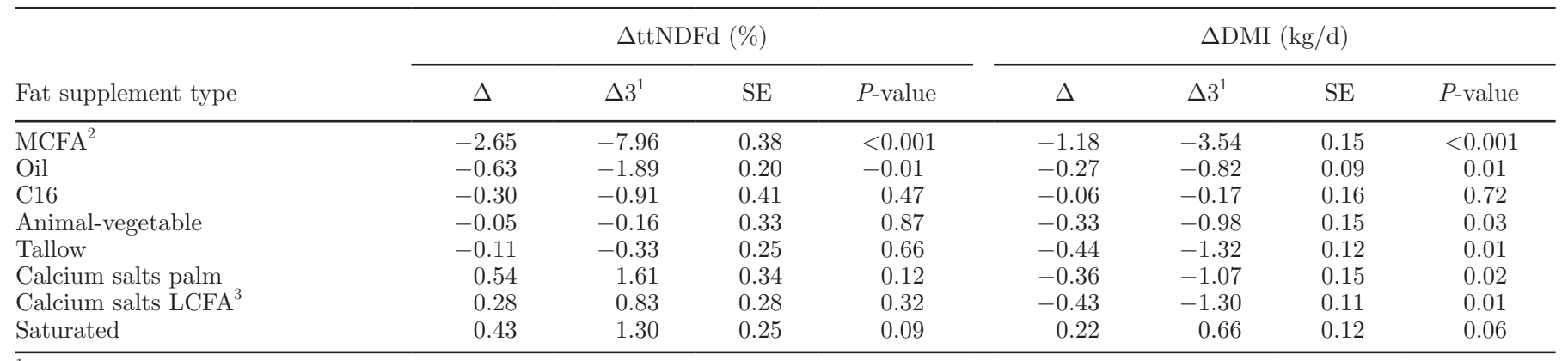

${ }^{1} \Delta 3=3 \times$ change $(\Delta)$ in DMI $/ 1 \%$ increase in diet fatty acids.

${ }^{2} \mathrm{MCFA}=$ medium-chain fatty acid, $\mathrm{C} 12$ and $\mathrm{C} 14$.

${ }^{3} \mathrm{LCFA}=$ long-chain fatty acid.

centage units/1\% FA), which has not been documented previously, though they were acknowledged as likely not having a negative effect (NRC, 2001). The magnitude of the increase was minimal, which could be why it was not detected in individual studies.

In the analysis of $\Delta$ ttNDFd/ $1 \% \mathrm{FA}, \mathrm{MCFA}$ is the only fat to significantly decrease ttNDFd $(-2.9$ percentage units/1\%FA; Table 6, Figure 2). In this analysis, calcium salts of LCFA increased ttNDFd relative to their low-fat controls (1.1 percentage units/1\%FA), which has been shown previously (Jenkins and Palmquist, 1984). The negative effect of oil in the previous model suggests that the positive effects of calcium salts of LCFA are not due to their FA profile. Perhaps the increase is a result of their properties as a salt; this is supported by the numeric increase of ttNDFd by calcium salts of palm oil ( 0.4 and 0.5 percentage units/1\% FA) in these analyses.

The mechanism behind the increased ttNDFd observed with calcium salts of LCFA compared with a low-fat control has yet to be fully elucidated. Calcium salts are not inert in the rumen in that they do interact with the rumen environment and undergo biohydrogenation (Van Nevel and Demeyer, 1996), though

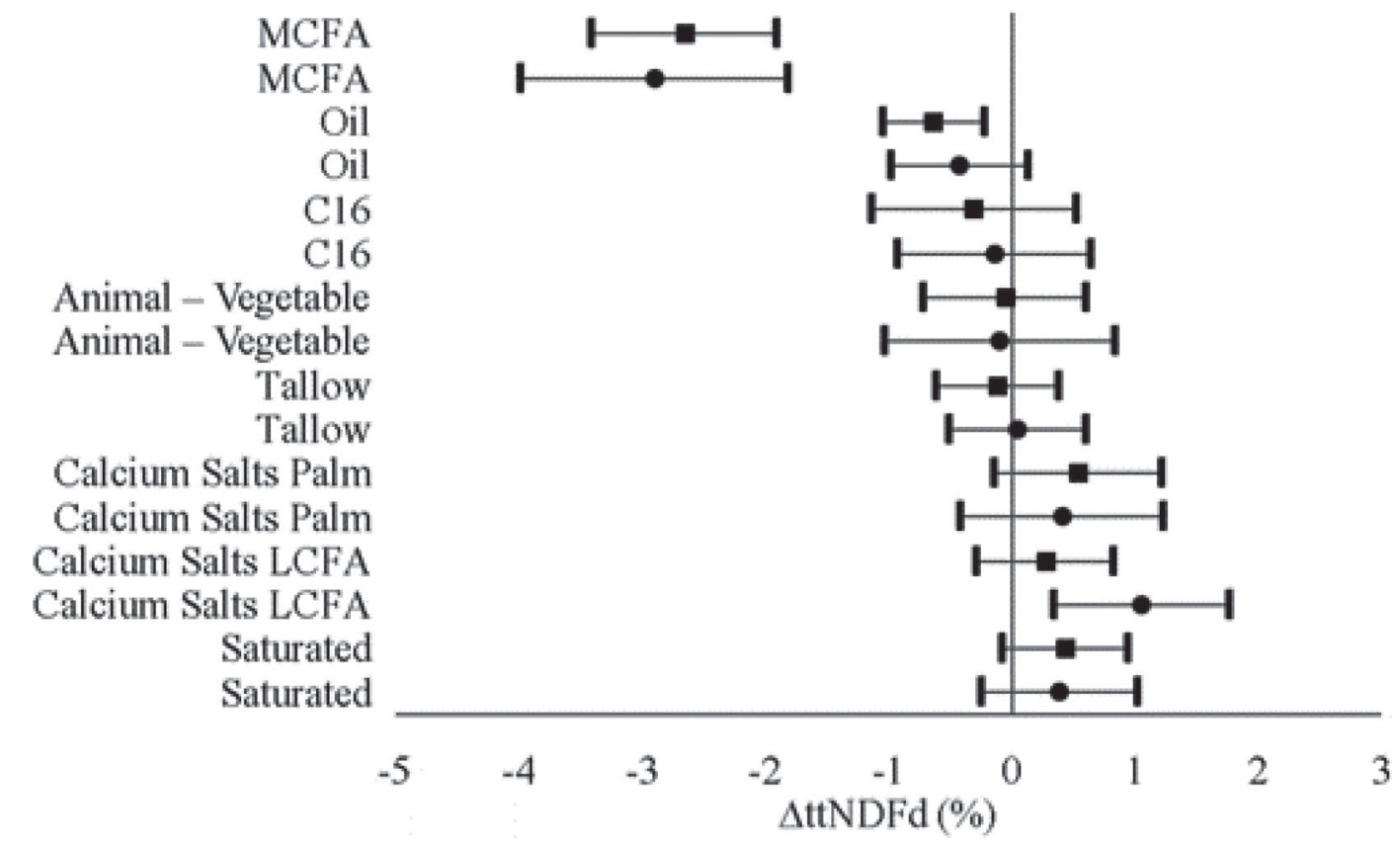

Figure 2. Forest plot of the mean change in total-tract NDF digestibility ( $\Delta$ ttNDFd) from both models. $\square=\Delta$ ttNDFd (regression model), $\boldsymbol{0}=\Delta \mathrm{ttNDFd} / 1 \%$ fatty acids (FA) (LSM model). MCFA = medium-chain fatty acid; LCFA = long-chain fatty acid. 
Table 6. Changes in DMI $(\Delta \mathrm{DMI} / 1 \% \mathrm{FA})$ and total-tract NDF digestibility per $1 \%$ change in fatty acid $(\Delta$ ttNDFd $/ 1 \% \mathrm{FA})$ when fat is supplemented to a lower-fat control diet based on an LSM model

\begin{tabular}{|c|c|c|c|c|c|c|c|c|}
\hline Fat supplement type & \multicolumn{4}{|c|}{$\Delta \mathrm{ttNDFd} / 1 \% \mathrm{FA}(\%)$} & \multicolumn{4}{|c|}{$\Delta \mathrm{DMI} / 1 \% \mathrm{FA}(\mathrm{kg} / \mathrm{d})$} \\
\hline$\overline{\mathrm{MCFA}^{2}}$ & $-2.89^{\mathrm{f}}$ & -8.67 & 0.54 & $<0.001$ & $-1.07^{\mathrm{C}}$ & -3.21 & 0.23 & $<0.001$ \\
\hline Oil & $-0.42^{\mathrm{e}}$ & -1.26 & 0.28 & 0.14 & $-0.31^{\mathrm{abc}}$ & -0.93 & 0.11 & 0.01 \\
\hline C16 & $-0.14^{\mathrm{de}}$ & -0.43 & 0.39 & 0.72 & $-0.12^{\mathrm{ab}}$ & -0.35 & 0.15 & 0.45 \\
\hline Animal-vegetable & $-0.09^{\mathrm{de}}$ & -0.28 & 0.47 & 0.84 & $-0.19^{\mathrm{ab}}$ & -0.57 & 0.18 & 0.31 \\
\hline Tallow & $0.05^{\mathrm{de}}$ & 0.14 & 0.28 & 0.86 & $-0.32^{\mathrm{abc}}$ & -0.96 & 0.12 & 0.01 \\
\hline Saturated fat & $0.39^{\mathrm{de}}$ & 1.17 & 0.32 & 0.23 & $0.23^{\mathrm{a}}$ & 0.68 & 0.13 & 0.09 \\
\hline
\end{tabular}

${ }^{\mathrm{a}-\mathrm{f}}$ Means without a common superscript differ within model $(P<0.05)$.

${ }^{1} \Delta 3=3 \times$ change $(\Delta)$ in $\mathrm{DMI} / 1 \%$ increase in diet fatty acids.

${ }^{2} \mathrm{MCFA}=$ medium-chain fatty acid, $\mathrm{C} 12$ and $\mathrm{C} 14$.

${ }^{3} \mathrm{LCFA}=$ long-chain fatty acid.

to a lesser extent than FA (Lundy et al., 2004). It is interesting to note that the average calcium content of the calcium salt diets was lower than that for the other fat-supplemented diets (mean \pm SD: $0.76 \pm 0.23$ and $0.99 \pm 0.14 \% \mathrm{DM}$, respectively). This suggests that the increase in ttNDFd when calcium salts are supplemented is not due to increased dietary calcium, but to another mechanism. It is possible that the UFA of calcium salts increase cholecystokinin release in the intestine (Bradford et al., 2008), thereby altering satiety and increasing digestibility (Harvatine and Allen, 2006). Though data showing that calcium salts significantly increased ttNDFd relative to control in individual studies is lacking, the combination of a small positive effect of calcium salts and a small negative effects of oils on ttNDFd may explain the greater fiber digestibility observed for calcium salts compared with other fat supplements (Jenkins and Palmquist, 1984; Doreau et al., 1993).

The models ( $\Delta$ ttNDFd/1\%FA, $\Delta$ ttNDFd) we tested are in agreement as to the direction of fat supplementation effects, though some differences exist in which effects reached significance between models. Overall, MCFA fats decrease ttNDFd to a degree having biological and statistical significance. Though this metaanalysis includes only 5 treatments in 2 publications, another study observed the same effects found in the meta-analysis but did not meet the requirements for inclusion (Hollmann and Beede, 2012). Those authors used 2 MCFA levels: $5 \%$ coconut oil or $2.5 \%$ coconut oil with $2.5 \%$ animal-vegetable fat. They were unable to complete the full trial, as the cows on $5 \%$ coconut oil diet were not healthy enough to continue the treatment. Data were only reported for the $2.5 \%$ treatment, in which decreases similar to those found for MCFA in the meta-analysis were observed. It can be expected that this decrease is due to the coconut oil, as our data shows that animal-vegetable fats have no effect on ttNDFd. The significant decrease is not surprising, as Soliva et al. (2004) showed synergistic negative effects of C12 and C14 on methanogens, which could affect hydrogen levels in the rumen. Henderson (1973) showed negative effects of MCFA on other genera, such as Ruminococcus, which is responsible for cellulose breakdown. In contrast to these negative effects, 2 studies found no effects of MCFA fat, 1 supplemented only $\mathrm{C} 12$, and the other used coconut oil, on ttNDFd (Hristov et al., 2009; Faciola and Broderick, 2014), though there were significant negative effects on the quantity of protozoa in the rumen (Faciola and Broderick, 2014), which are responsible for some fiber breakdown (Hobson and Steward, 1997). Therefore, negative effects of C12 and $\mathrm{C} 14 \mathrm{FA}$ exist, but this is not always the case. We cannot conclude from this analysis what effect basal levels of $\mathrm{C} 12$ and C14 FA may have on ttNDFd even in lowfat diets.

Though oil has a statistically significant negative effect on ttNDFd, the change was only a 2 percentage unit decrease in ttNDFd at 3\% FA supplementation. In a typical dairy cow ration, $3 \%$ addition of fat is equivalent to at least $0.6 \mathrm{~kg}$ of oil. In most cases, if this much free oil were fed negative effects on milk fat yield would likely be noted as well (He et al., 2012; Ramirez Ramirez et al., 2015; Stoffel et al., 2015), so oil additions at this level are generally avoided. It has been demonstrated that UFA can alter the microbial profile of the rumen (Ueda et al., 2003; Reveneau et al., 2012), possibly through the negative effects on the microbial membranes (Maia et al., 2007). Fats have been shown to be associated with the solid portion of the rumen mass (Legay-Carmier and Bauchart, 1989), though no evidence has shown if they directly interfere with 
fiber breakdown. Ultimately, though the 2 percentage unit decrease in ttNDFd is statistically significant, it is minimal compared with the increased dietary energy density from added fat, which will be addressed later in this discussion.

The increased ttNDFd when saturated fats were supplemented may be related to their lack of effects on the ruminal environment, as they are already almost completely saturated and will have minimal negative effects on microbes (Maia et al., 2010). However, we have no explanation for why $\Delta$ ttNDFd is positive rather than zero, though it is of a small magnitude. In contrast to our findings, a study not included in our data set fed $5 \%$ saturated fats to nonlactating cows and observed an average 6 percentage unit decrease in ttNDFd (Elliott et al., 1994). However, it is possible that some of this difference is due to the lower intake multiples of maintenance in dry cows (Moe et al., 1965). The other variables that could explain differences between dry cows and lactating cows differ in the remainder of the diet, including fiber sources and starch levels, which may have an effect on how fat affects fiber digestibility (Palmquist and Jenkins, 1980). However, a lack of evidence exists of an interaction between fat supplementation and forage type (Smith et al., 1993; Ruppert et al., 2003), and no interaction was determined to be significant in this analysis. The presence of a main effect in the model would have been an interaction due to the analysis of the data as a change from control.

In $90 \%$ of the treatments, fat at least partially replaced corn in the diets; therefore, the proportion of starch is decreased in the treatment diets and ttNDFd is increased approximately $0.5 \%$ for each 1 percentage unit decrease in starch (Ferraretto et al., 2013). Thus, though the data are presented as differences from controls due to addition of fat, it must be kept in mind that the treatment diets had reduced concentrations of starch and other constituents compared with control diets. On average, all diets had an increase in the sum of the NFC and FA fractions (NFC+FA; Table 3), which indicates that FA were substituted for other diet components in addition to NFC. This makes sense, as even if the FA were substituted for corn, some CP and NDF would be replaced. In the case of MCFA the increase in NFC+FA is not sufficient to explain the decreases observed in ttNDFd. The increase in NFC+FA could explain part of the decreased ttNDFd for oil supplemented diets. If FA depress fiber digestibility similarly to starch, as this data set suggests, then a 2 percentage unit increase in $\mathrm{NFC}+\mathrm{FA}$ would result in a 1 percentage unit decrease in ttNDFd. This change is half of what was observed for oil supplementation. The change in $\mathrm{NFC}+\mathrm{FA}$ is numerically less for calcium salts of LCFA and saturated fats compared with oils and C16, which could be part of the mechanism behind the increased $\Delta$ ttNDFd that are observed for calcium salts of LCFA and saturated fat. However, the lack of difference from no change for most of the fat supplements suggests that most fats have the same effect on fiber digestibility as what they replace in the diet, primarily starch.

\section{Rumen NDF Digestibility}

If fat directly suppressed NDF digestion at the site of fermentation, it is reasonable to speculate that fat could reduce NDF digestion in the rumen (rumenNDFd). Then, as fat is absorbed in the small intestine, the resulting digestible NDF escaping the rumen would be fermented in the large intestine. In this scenario, ttNDFd would be much less sensitive to fat effects than rumenNDFd. There are not enough data available for a formal statistical analysis on the changes in rumenNDFd by type of fat in this data set. Three studies, Doreau et al. (1993), Chelikani et al. (2004), and Brask et al. (2013), reported rumenNDFd to be greater than ttNDFd. Those studies were included based on the assumption that, by looking at the difference from the control to treatment, we controlled for the methodology error that was presumably present. The average change in rumenNDFd from fat addition ( $\Delta$ rumenNDFd) across fat types is a 0.4 percentage unit increase (Table 7), which contrasts with data from steers demonstrating severe negative effects of fat on rumen fiber digestibility that is made up for in the hindgut (Jenkins and Palmquist, 1984; Zinn, 1989).

The lack of a decrease in rumenNDFd might suggest that, although bacteria can be negatively affected by the addition of fat to the diet, especially unsaturated fats, the microbes responsible for fiber digestion are not significantly affected. This is plausible, as in vitro work has shown that bacterial metabolism has an effect on its susceptibility to high FA concentrations (Maia et al., 2007). Because this work was done in vitro, it is possible that this may not be the case in vivo, where substrate availability and passage rate are constantly changing the bacterial population. However, the changes in ttNDFd and rumenNDFd disagree in this data set. For oil, the mean $\Delta$ ttNDFd for studies that include a rumenNDFd is -1.4 percentage units, which contrasts with the positive number, 3.7 , found for $\Delta$ rumenNDFd. Rumen digestibility is typically a more variable measurement than that for total-tract digestibility (Ueda et al., 2003; Reveneau et al., 2012; Brask et al., 2013), though this does not fully explain the discrepancies noted between $\triangle$ rumenNDFd and $\Delta$ ttNDFd. The lack of a negative effect on rumenNDFd 


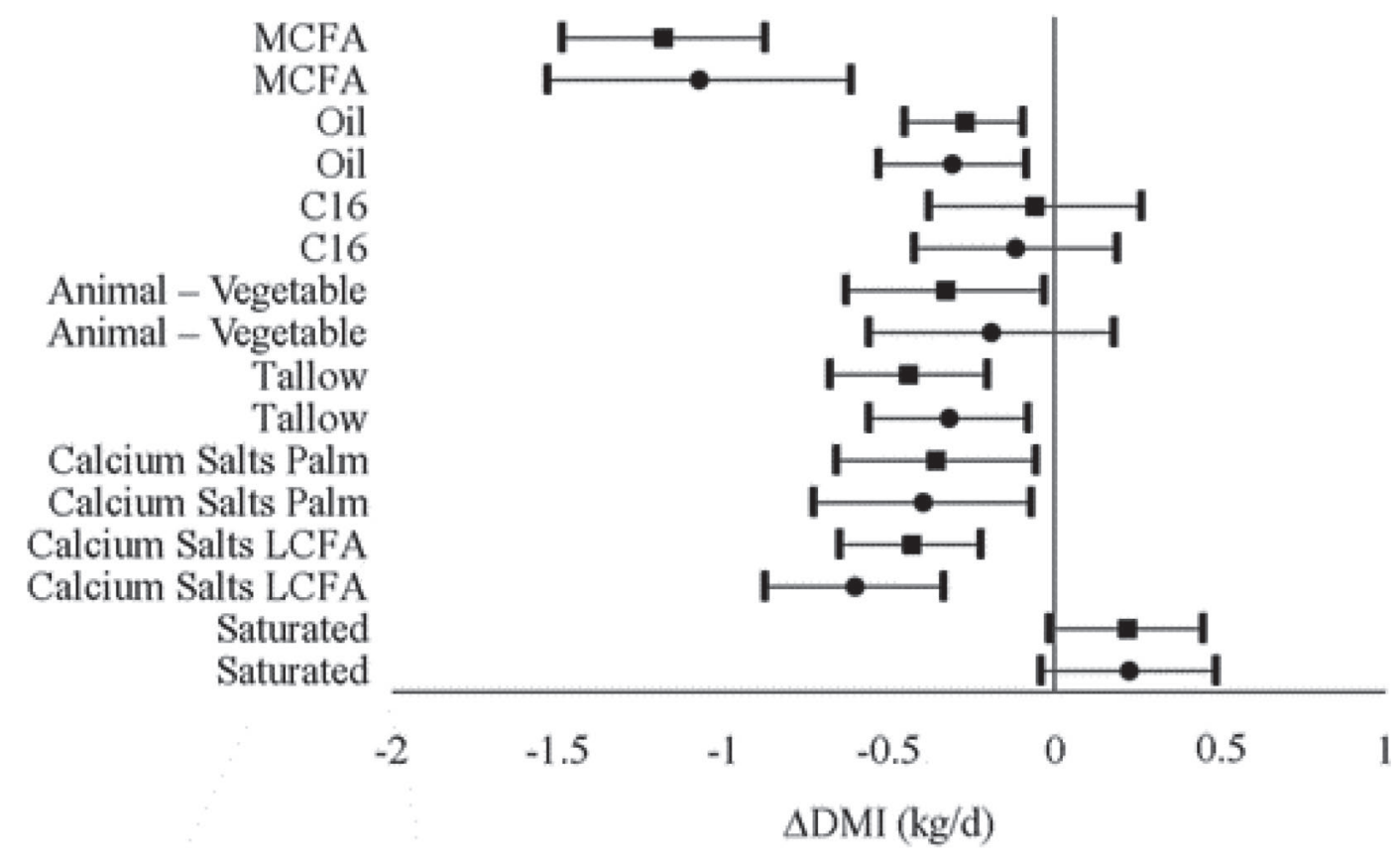

Figure 3. Forest plot of the change in DMI ( $\Delta$ DMI) from both models. $\mathbf{\square}=\Delta \mathrm{DMI}$ (regression model), $\bullet=\Delta \mathrm{DMI} / 1 \%$ fatty acids $(\mathrm{FA})$ (LSM model). MCFA = medium-chain fatty acid; LCFA = long-chain fatty acid.

supports our conclusion that a ttNDFd decrease due to oil supplementation is not biologically significant.

\section{DMI}

Changes in DMI were examined as a possible mechanism by which to explain changes in ttNDFd. One study in the data set did not report DMI and, therefore, was excluded from the analysis for DMI (Palmquist, 1991). For in-depth review of the effects of fat supplementation on intake, see Allen (2000). In the model for $\triangle \mathrm{DMI}$, all fats, except $\mathrm{C} 16$ and saturated fats, significantly decreased DMI $(-0.8$ to -3.5 $\mathrm{kg} / 3 \% \mathrm{FA}$ ), and saturated fats tended to increase DMI $(0.7 \mathrm{~kg} / 3 \% \mathrm{FA})$. The quadratic effect of $\Delta \mathrm{FA}$ was not significant $(P>0.10)$ and diet FA provided a poorer fit than $\triangle \mathrm{FA}$ in validating the analysis of the data as a linear change. Oil, MCFA, tallow, calcium salts of palm oil, and calcium salts of LCFA significantly decreased $\Delta \mathrm{DMI} / 1 \% \mathrm{FA}(-1.1$ to $-0.3 \mathrm{~kg}$ of $\mathrm{DMI} / 1 \% \mathrm{FA})$, and saturated fats tended to increase it ( $0.2 \mathrm{~kg}$ of DMI/1\% FA; Tables 5 and 6, Figure 3).

The results from these 2 models are in agreement with the literature, which has shown decreases in DMI when fat is supplemented to the diets of lactating dairy cattle (Rabiee et al., 2012; Allen, 2000). Many of the studies used in this meta-analysis used mid-lactation cows that presumably were able to meet their energy needs for lactation without fat supplementation. Therefore, the increased dietary energy density with fat supplementa-

Table 7. Unweighted means of ruminal NDF digestibility (rumenNDFd)

\begin{tabular}{lcccc}
\hline & \multicolumn{4}{c}{ rumenNDFd (\%, mean $\pm \mathrm{SD})$} \\
\cline { 2 - 5 } Fat supplement type $^{1}$ & $\mathrm{~N}$ & Control & Treatment & $\Delta$ \\
\hline MCFA $^{2}$ & 2 & $31.1 \pm 3.9$ & $23.8 \pm 11.0$ & -7.3 \\
Oil & 5 & $51.8 \pm 11.7$ & $55.5 \pm 14.0$ & +3.7 \\
Animal-vegetable & 4 & $39.5 \pm 10.0$ & $38.1 \pm 9.0$ & -1.4 \\
Tallow & 1 & 46.9 & 53.5 & +6.6 \\
Calcium salts LCFA & 2 & $48.1 \pm 27.2$ & $49.6 \pm 24.6$ & +1.5 \\
Saturated fat & 2 & $38.9 \pm 14.2$ & $38.0 \pm 19.0$ & -0.9 \\
Total & 16 & $43.7 \pm 13.2$ & $44.1 \pm 16.3$ & +0.4 \\
\hline
\end{tabular}

${ }^{1}$ No calcium salts of palm oil treatments reported rumenNDFd; $\Delta=$ treatment - control.

${ }^{2} \mathrm{MCFA}=$ medium-chain fatty acid.

${ }^{3} \mathrm{LCFA}=$ long-chain fatty acid. 
tion could have allowed the decrease in DMI while still meeting the cows' energy requirements.

\section{Relationship Between $\triangle t t N D F d$ and $\triangle D M I$}

A negative relationship between DMI and ttNDFd could arise from higher DMI increasing passage rate and reducing NDF digestion (Tyrrell and Moe, 1975). A positive relationship between ttNDFd and DMI could arise from increased NDF digestion causing less rumen fill and greater DMI, as shown by Oba and Allen (1999). In our data set, a significant positive relationship existed between $\triangle$ ttNDFd and $\triangle$ DMI (Figure 4). However, significance must be interpreted with caution, as the coefficient of determination was low $\left(R^{2}=0.06\right)$. The inclusion of MCFA fats in the regression analysis improved the fit of the model $\left(\mathrm{R}^{2}=0.20\right)$ because of their more extreme changes in both ttNDFd and DMI compared with other fat types. As these are differences

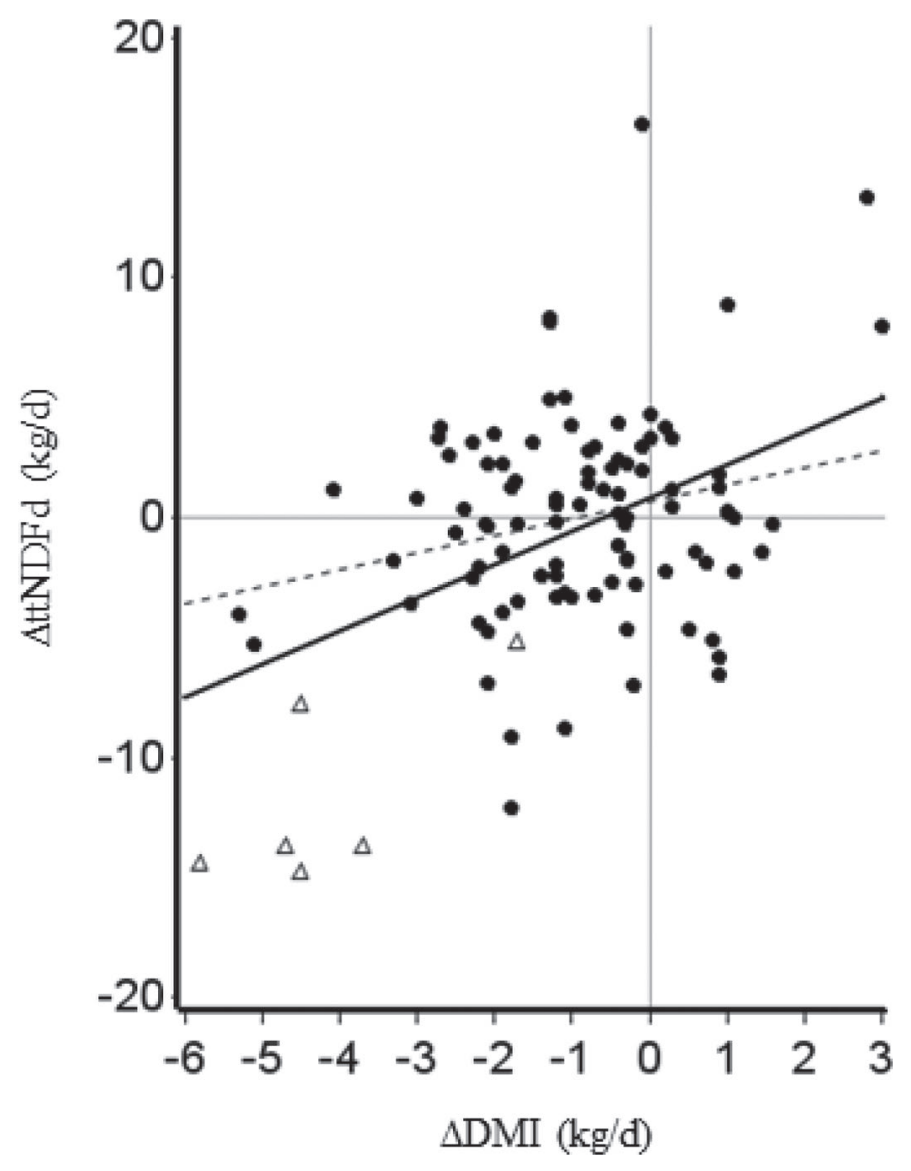

Figure 4. Change in total-tract NDF digestibility ( $\Delta$ ttNDFd) versus change in DMI $(\Delta \mathrm{DMI})$ for all types of fat supplement. $\Delta=$ medium-chain fatty acid (FA), $\bullet=$ all others except medium-chain FA. Regression for all (solid line): $\Delta$ ttNDFd $=\Delta$ DMI $\times 1.39(P<0.0001)$ $+0.84, \mathrm{R}^{2}=0.20$; Regression without medium-chain FA (dashed line): $\Delta \mathrm{ttNDFd}=\Delta \mathrm{DMI} \times 0.71(P=0.02)+0.84, \mathrm{R}^{2}=0.06$. from control, study variation has presumably been controlled for.

In contrast to the slight positive relationship between DMI and ttNDFd seen across the whole data set, we theorized a possible negative relationship for calcium salts of LCFA and palm because their means exhibited a decrease in $\triangle D M I$ and an increase in $\Delta$ ttNDFd. However, no relationship was found between $\Delta$ ttNDFd and $\triangle$ DMI (data not shown) within calcium salts. Other possible causes besides passage rate for the decrease in DMI observed with calcium salt supplementation are palatability (Grummer et al., 1990), satisfying the energy requirements at lower intakes due to increased energy density, or changes in passage rate and digestibility due to gut hormone release (Bradford et al., 2008). Saturated fats are the only fat type to have a significant relationship between $\triangle \mathrm{DMI}$ and $\Delta$ ttNDFd, and this relationship was positive. This could suggest that cows were able to increase their DMI when ttNDFd was increased. Potential exists that $\Delta \mathrm{DMI}$ explains some of the variability in $\Delta$ ttNDFd across fat types; however, more studies are needed to better characterize the relationship between $\triangle \mathrm{DMI}$ and $\Delta \mathrm{ttNDFd}$ with specific fat supplements and determine causative mechanisms.

\section{TDN Changes}

When fat replaces either protein or carbohydrates in a diet, it increases the dietary energy density. Therefore, an animal would be required to consume less feed to meet their energy requirements, which may be the case in this group of studies where many were mid-lactation cows. However, for high-producing dairy cattle, especially those in early lactation that are in negative energy balance, there are different constraints on intake such as fill and passage rate (Moe et al., 1965).

In this data set, the decreases in DMI had a greater negative effect on TDN intake than did any negative changes in ttNDFd. This resulted in some predicted net negative changes in TDN $(\triangle T D N)$ intakes when fat is supplemented $(-2.1$ to $-0.1 \mathrm{~kg} / \mathrm{d})$ even though TDN concentration of the diet increased (Table 8). Therefore, when adding fat to a diet, more emphasis should be placed on potential DMI decreases than decreases in ttNDFd. Changes in DMI affect the energy derived from all nutrients, whereas changes in ttNDFd only affect NDF. Though NDF is a large portion of the diet, the NFC portion is at least as large and more digestible (NRC, 2001). The increased energy density of the diet when fat is added was not enough to maintain TDN intake when DMI decreased significantly. The small decreases in ttNDFd did not cause decreased TDN intake in any fat-supplemented diets except when MCFA or oil were supplemented. 
Table 8. Predicted changes in TDN intake ( $\triangle$ TDN) due to changes in DMI and total-tract NDF digestibility (ttNDFd) when $3 \%$ supplemental fatty acid (FA) is added to the diet

\begin{tabular}{|c|c|c|c|c|}
\hline \multirow[b]{2}{*}{ Fat supplement type } & \multicolumn{4}{|c|}{ Predicted $\Delta$ TDN $(\mathrm{kg} / \mathrm{d})^{1}$} \\
\hline & $\Delta \mathrm{FA}$ & $\Delta \mathrm{DMI}$ & $\Delta \mathrm{ttNDFd}$ & Net \\
\hline $\mathrm{MCFA}^{2}$ & +0.6 & -2.1 & -0.6 & -2.1 \\
\hline Oil & +0.6 & -0.6 & -0.1 & -0.1 \\
\hline $\mathrm{C} 16$ & +0.6 & -0.2 & 0.0 & +0.4 \\
\hline Animal -vegetable & +0.6 & -0.4 & 0.0 & +0.2 \\
\hline Tallow & +0.6 & -0.6 & 0.0 & 0.0 \\
\hline Calcium salts palm & +0.6 & -0.8 & +0.1 & -0.1 \\
\hline Calcium salts LCFA ${ }^{3}$ & +0.6 & -1.2 & +0.2 & -0.4 \\
\hline Saturated fat & +0.6 & +0.5 & +0.1 & +1.2 \\
\hline
\end{tabular}

${ }^{1}$ Means from $\Delta \mathrm{ttNDFd} / 1 \% \mathrm{FA}$ and $\Delta \mathrm{DMI} / 1 \% \mathrm{FA}$ were utilized. $\Delta \mathrm{FA}$ is the increase in TDN intake due to the increased energy density of the diet with $3 \%$ fat supplementation, $\triangle \mathrm{DMI}$ is the change in TDN intake with a fat supplemented diet with and without a change in DMI due to fat supplementation, $\Delta$ ttNDFd is the change in TDN intake with a fat supplemented diet with and without a change in ttNDFd due to fat supplementation.

${ }^{2} \mathrm{MCFA}=$ medium-chain fatty acid.

${ }^{3} \mathrm{LCFA}=$ long-chain fatty acid.

The digestibility of fat supplements was not altered from $75 \%$ for the purpose of this simulation. There is a range of fat digestibility across fat supplement types, with calcium salts generally having higher digestibilities than hydrogenated fats due to the difference in C18:0 content (NRC, 2001; Boerman et al., 2015). Therefore, the differences in $\triangle T D N$ intake may not be quite as large as they appear, particularly between calcium salts, negative $\triangle \mathrm{TDN}$, and hydrogenated fats, positive $\Delta$ TDN (Table 8).

\section{CONCLUSIONS}

Dietary SFA with 12 or 14 carbons reduced ttNDFd and DMI. Oils appear to have had only a small negative effects on ttNDFd, but these were relatively unimportant at levels of oils typically fed, and ttNDFd changes were small compared with changes in DMI and energy density increases due to substituting fat for carbohydrate. Inclusion of calcium salts of LCFA or saturated fats may have actually increased ttNDFd. No other 16- or 18-carbon fat significantly affected ttNDFd, and these fats also do not appear to have had significant effects on rumen NDF digestibility at levels fed in these studies. The increased ttNDFd due to the supplementation of calcium salts was not related to concurrent decreases in DMI, indicating another mechanism besides changes in DMI is responsible for the ttNDFd increase.

\section{REFERENCES}

Aldrich, C. G., N. R. Merchen, J. K. Drackley, G. C. Fahey, and L. L. Berger. 1997. The effects of chemical treatment of whole canola seed on intake, nutrient digestibilities, milk production, and milk fatty acids of Holstein cows. J. Anim. Sci. 75:512-521.
Allen, M. S. 2000. Effects of diet on short-term regulation of feed intake by lactating dairy cattle. J. Dairy Sci. 83:1598-1624.

Avila, C. D., E. J. DePeters, H. Perez-Monti, S. J. Taylor, and R. A. Zinn. 2000. Influences of saturation ratio of supplemental dietary fat on digestion and milk yield in dairy cows. J. Dairy Sci. 83:1505-1519.

Benchaar, C., F. Hassanat, R. Martineau, and R. Gervais. 2015. Linseed oil supplementation to dairy cows fed diets based on red clover silage or corn silage: Effects on methane production, rumen fermentation, nutrient digestibility, $\mathrm{N}$ balance, and milk production. J. Dairy Sci. 98:7993-8008.

Benchaar, C., G. A. Romero-Pérez, P. Y. Chouinard, F. Hassanat, M. Eugene, H. V. Petit, and C. Côrtes. 2012. Supplementation of increasing amounts of linseed oil to dairy cows fed total mixed rations: Effects on digestion, ruminal fermentation characteristics, protozoal populations, and milk fatty acid composition. J. Dairy Sci. 95:4578-4590.

Boerman, J. P., J. L. Firkins, N. R. St-Pierre, and A. L. Lock. 2015. Intestinal digestibility of long-chain fatty acids in lactating dairy cows: A meta-analysis and meta-regression. J. Dairy Sci. 98:88898903.

Bradford, B. J., K. J. Harvatine, and M. S. Allen. 2008. Dietary unsaturated fatty acids increase plasma glucagon-like peptide-1 and cholecystokinin and may decrease premeal ghrelin in lactating dairy cows. J. Dairy Sci. 91:1443-1450.

Brask, M., P. Lund, M. R. Weisbjerg, A. L. F. Hellwing, M. Poulsen, M. K. Larsen, and T. Hvelplund. 2013. Methane production and digestion of different physical forms of rapeseed as fat supplements in dairy cows. J. Dairy Sci. 96:2356-2365.

Chelikani, P. K., J. A. Bell, and J. J. Kennelly. 2004. Effects of feeding or abomasal infusion of canola oil in Holstein cows-1. Nutrient digestion and milk composition. J. Dairy Res. 71:279-287.

Chouinard, P. Y., V. Girard, and G. J. Brisson. 1998. Fatty acid profile and physical properties of milk fat from cows fed calcium salts of fatty acids with varying unsaturation. J. Dairy Sci. 81:471-481.

DeLuca, D. D., and T. C. Jenkins. 2000. Feeding oleamide to lactating Jersey cows. 2. Effects on nutrient digestibility, plasma fatty acids, and hormones. J. Dairy Sci. 83:569-576.

DePeters, E. J., S. J. Taylor, C. M. Finley, and T. R. Famula. 1987. Dietary-fat and nitrogen composition of milk from lactating cows. J. Dairy Sci. 70:1192-1201.

Devendra, C., and D. Lewis. 1974. The interaction between dietary lipids and fibre in the sheep 2. Digestibility studies. Anim. Prod. 19:67-76.

Do Prado, R. M., C. Cortes, C. Benchaar, and H. V. Petit. 2015. Interaction of sunflower oil with monensin on milk composition, milk 
fatty acid profile, digestion, and ruminal fermentation in dairy cows. Anim. Feed Sci. Technol. 207:85-92.

Doreau, M., A. Ferlay, and Y. Elmeddah. 1993. Organic matter and nitrogen digestion by dairy-cows fed calcium salts of rapeseed oil fatty-acids or rapeseed oil. J. Anim. Sci. 71:499-504.

Drackley, J. K., and J. P. Elliott. 1993. Milk composition, ruminal characteristics, and nutrient utilization in dairy-cows fed partially hydrogenated tallow. J. Dairy Sci. 76:183-196.

Drackley, J. K., D. E. Grum, G. C. McCoy, and T. H. Klusmeyer. 1994. Comparison of three methods for incorporation of liquid fat into diets for lactating dairy cows. J. Dairy Sci. 77:1386-1398.

Eastridge, M. L., and J. L. Firkins. 2000. Feeding tallow triglycerides of different saturation and particle size to lactating dairy cows. Anim. Feed Sci. Technol. 83:249-259.

Elliott, J. P., J. K. Drackley, and D. J. Weigel. 1996. Digestibility and effects of hydrogenated palm fatty acid distillate in lactating dairy cows. J. Dairy Sci. 79:1031-1039.

Elliott, J. P., T. R. Overton, and J. K. Drackley. 1994. Digestibility and effects of 3 forms of mostly saturated fatty acids. J. Dairy Sci. 77:789-798.

Enjalbert, F., M. C. Nicot, C. Bayourthe, M. Vernay, and R. Moncoulon. 1997. Effects of dietary calcium soaps of unsaturated fatty acids on digestion, milk composition and physical properties of butter. J. Dairy Res. 64:181-195.

Faciola, A. P., and G. A. Broderick. 2013. Effects of feeding lauric acid on ruminal protozoa numbers, fermentation, and digestion and on milk production in dairy cows. J. Anim. Sci. 91:2243-2253.

Faciola, A. P., and G. A. Broderick. 2014. Effects of feeding lauric acid or coconut oil on ruminal protozoa numbers, fermentation pattern, digestion, omasal nutrient flow, and milk production in dairy cows. J. Dairy Sci. 97:5088-5100.

Ferraretto, L. F., P. M. Crump, and R. D. Shaver. 2013. Effect of cereal grain type and corn grain harvesting and processing methods on intake, digestion, and milk production by dairy cows through a meta-analysis. J. Dairy Sci. 96:533-550.

Freitas, J. E., Jr., F. P. Renno, J. R. Gandra, L. N. Renno, A. C. Rego, M. V. Santos, M. D. S. Oliveira, and C. S. Takiya. 2014. Addition of unsaturated fatty acids improves digestion of mid lactating dairy cows. Arch. Zootec. 63:563-573.

Grummer, R. R., M. L. Hatfield, and M. R. Dentine. 1990. Acceptability of fat supplements in four dairy herds. J. Dairy Sci. 73:852-857.

Harvatine, K. J., and M. S. Allen. 2006. Effects of fatty acid supplements on ruminal and total tract nutrient digestion in lactating dairy cows. J. Dairy Sci. 89:1092-1103.

He, M., K. L. Perfield, H. B. Green, and L. E. Armentano. 2012. Effect of dietary fat blend enriched in oleic or linoleic acid and monensin supplementation on dairy cattle performance, milk fatty acid profiles, and milk fat depression. J. Dairy Sci. 95:1447-1461.

Henderson, C. 1973. The effects of fatty acids on pure cultures of rumen bacteria. J. Agric. Sci. 81:107-112.

Hobson, P. N., and C. S. Steward, ed. 1997. Rumen Microbial Ecosystem. Chapman and Hall, London, UK.

Hollmann, M., and D. K. Beede. 2012. Comparison of effects of dietary coconut oil and animal fat blend on lactational performance of Holstein cows fed a high-starch diet. J. Dairy Sci. 95:1484-1499.

Hristov, A. N., M. V. Pol, M. Agle, S. Zaman, C. Schneider, P. Ndegwa, V. K. Vaddella, K. Johnson, K. J. Shingfield, and S. K. R. Karnati. 2009. Effect of lauric acid and coconut oil on ruminal fermentation, digestion, ammonia losses from manure, and milk fatty acid composition in lactating cows. J. Dairy Sci. 92:5561-5582.

Jenkins, T. C. 1993. Lipid metabolism in the rumen. J. Dairy Sci. 76:3851-3863.

Jenkins, T. C. 1998. Fatty acid composition of milk from Holstein cows fed oleamide or canola oil. J. Dairy Sci. 81:794-800.

Jenkins, T. C., and D. L. Palmquist. 1984. Effect of fatty acids or calcium soaps on rumen and total nutrient digestibility of dairy rations. J. Dairy Sci. 67:978-986.

Kargar, S., G. R. Ghorbani, M. Alikhani, M. Khorvash, L. Rashidi, and D. J. Schingoethe. 2012. Lactational performance and milk fatty acid profile of Holstein cows in response to dietary fat supplements and forage:concentrate ratio. Livest. Sci. 150:274-283.
Lapierre, H., R. Berthiaume, G. Raggio, M. C. Thivierge, L. Doepel, D. Pacheco, P. Dubreuil, and G. E. Lobley. 2005. The route of absorbed nitrogen into milk protein. Anim. Sci. 80:11-22.

Lee, C., and A. N. Hristov. 2014. Short communication: Comparison of 3 solid digesta passage markers in dairy cows. J. Dairy Sci. 97:1725-1729.

Legay-Carmier, F., and D. Bauchart. 1989. Distribution of bacteria in the rumen contents of dairy cows given a diet supplemented with soya-bean oil. Br. J. Nutr. 61:725-740.

Lundy, F. P., III, E. Block, W. C. Bridges Jr., J. A. Bertrand, and T. C. Jenkins. 2004. Ruminal biohydrogenation in Holstein cows fed soybean fatty acids as amides or calcium salts. J. Dairy Sci. $87: 1038-1046$.

Maia, M. R. G., L. C. Chaudhary, C. S. Bestwick, A. J. Richardson, N. McKain, T. R. Larson, I. A. Graham, and R. J. Wallace. 2010. Toxicity of unsaturated fatty acids to the biohydrogenating ruminal bacterium, Butyrivibrio fibrisolvens. BMC Microbiol. 10:52. https://doi.org/10.1186/1471-2180-10-52.

Maia, M. R. G., L. C. Chaudhary, L. Figueres, and R. J. Wallace. 2007. Metabolism of polyunsaturated fatty acids and their toxicity to the microflora of the rumen. Antonie Van Leeuwenhoek 91:303-314

Martin, C., J. Rouel, J. P. Jouany, M. Doreau, and Y. Chilliard. 2008. Methane output and diet digestibility in response to feeding dairy cows crude linseed, extruded linseed, or linseed oil. J. Anim. Sci. $86: 2642-2650$.

Moe, P. W., J. T. Reid, and H. F. Tyrrell. 1965. Effect of level of intake on digestibility of dietary energy by high-producing cows. J. Dairy Sci. 48:1053-1061.

NRC. 2001. Nutrient Requirements of Dairy Cattle. 7th rev. ed. Natl. Acad. Press, Washington DC.

Oba, M., and M. S. Allen. 1999. Evaluation of the importance of the digestibility of neutral detergent fiber from forage: Effects on dry matter intake and milk yield of dairy cows. J. Dairy Sci. 82:589596.

Palmquist, D. L. 1991. Influence of source and amount of dietary-fat on digestibility in lactating cows. J. Dairy Sci. 74:1354-1360.

Palmquist, D. L., and T. C. Jenkins. 1980. Fat in lactation rationsReview. J. Dairy Sci. 63:1-14.

Pantoja, J., J. L. Firkins, and M. L. Eastridge. 1996. Fatty acid digestibility and lactation performance by dairy cows fed fats varying in degree of saturation. J. Dairy Sci. 79:429-437.

Pantoja, J., J. L. Firkins, M. L. Eastridge, and B. L. Hull. 1994. Effects of fat saturation and source of fiber on site of nutrient digestion and milk production by lactating dairy cows. J. Dairy Sci. $77: 2341-2356$

Piantoni, P., A. L. Lock, and M. S. Allen. 2013. Palmitic acid increased yields of milk and milk fat and nutrient digestibility across production level of lactating cows. J. Dairy Sci. 96:7143-7154.

Piantoni, P., A. L. Lock, and M. S. Allen. 2015. Milk production responses to dietary stearic acid vary by production level in dairy cattle. J. Dairy Sci. 98:1938-1949.

Rabiee, A. R., K. Breinhild, W. Scott, H. M. Golder, E. Block, and I. J. Lean. 2012. Effect of fat additions to diets of dairy cattle on milk production and components: A meta-analysis and metaregression. J. Dairy Sci. 95:3225-3247.

Ramirez Ramirez, H. A., E. Castillo Lopez, K. J. Harvatine, and P. J. Kononoff. 2015. Fat and starch as additive risk factors for milk fat depression in dairy diets containing corn dried distillers grains with solubles. J. Dairy Sci. 98:1903-1914.

Reveneau, C., S. K. R. Karnati, E. R. Oelker, and J. L. Firkins. 2012 Interaction of unsaturated fat or coconut oil with monensin in lactating dairy cows fed 12 times daily. I. Protozoal abundance, nutrient digestibility, and microbial protein flow to the omasum. J. Dairy Sci. 95:2046-2060

Rico, D. E., Y. Ying, and K. J. Harvatine. 2014. Effect of a highpalmitic acid fat supplement on milk production and apparent total-tract digestibility in high- and low-milk yield dairy cows. J. Dairy Sci. 97:3739-3751.

Ruppert, L. D., J. K. Drackley, D. R. Bremmer, and J. H. Clark. 2003. Effects of tallow in diets based on corn silage or alfalfa silage on 
digestion and nutrient use by lactating dairy cows. J. Dairy Sci. 86:593-609.

Schauff, D. J., J. P. Elliott, J. H. Clark, and J. K. Drackley. 1992. Effects of feeding lactating dairy-cows diets containing whole soybeans and tallow. J. Dairy Sci. 75:1923-1935.

Smith, W. A., B. Harris, H. H. Vanhorn, and C. J. Wilcox. 1993. Effects of forage type on production of dairy-cows supplemented with whole cottonseed, tallow, and yeast. J. Dairy Sci. 76:205-215.

Soliva, C. R., L. Meile, I. K. Hindrichsen, M. Kreuzer, and A. Machmuller. 2004. Myristic acid supports the immediate inhibitory effect of lauric acid on ruminal methanogens and methane release. Anaerobe 10:269-276.

St-Pierre, N. R. 2001. Invited review: Integrating quantitative findings from multiple studies using mixed model methodology. J. Dairy Sci. 84:741-755.

Stoffel, C. M., P. M. Crump, and L. E. Armentano. 2015. Effect of dietary fatty acid supplements, varying in fatty acid composition, on milk fat secretion in dairy cattle fed diets supplemented to less than 3\% total fatty acids. J. Dairy Sci. 98:431-442.

Tyrrell, H. F., and P. W. Moe. 1975. Effect of intake on digestive efficiency. J. Dairy Sci. 58:1151-1163.

Ueda, K., A. Ferlay, J. Chabrot, J. J. Loor, Y. Chilliard, and M. Doreau. 2003. Effect of linseed oil supplementation on ruminal digestion in dairy cows fed diets with different forage:concentrate ratios. J. Dairy Sci. 86:3999-4007.
Van Nevel, C. J., and D. I. Demeyer. 1996. Effect of pH on biohydrogenation of polyunsaturated fatty acids and their Ca-salts by rumen microorganisms in vitro. Arch. Tierenahr. 49:151-157.

Ward, J. K., C. W. Tefft, R. J. Sirny, H. N. Edwards, and A. D. Tillman. 1957. Further studies concerning the effect of alfalfa ash upon the utilization of low-quality roughages by ruminant animals. J. Anim. Sci. 16:633-641.

Weigel, D. J., J. P. Elliott, and J. H. Clark. 1997. Effects of amount and ruminal degradability of protein on nutrient digestibility and production by cows fed tallow. J. Dairy Sci. 80:1150-1159.

Weiss, W. P. J. M. Pinos-Rodríguez, and D. J. Wyatt. 2011. The value of different fat supplements as sources of digestible energy for lactating dairy cows. J. Dairy Sci. 94:931-939.

Weiss, W. P., and D. J. Wyatt. 2004. Digestible energy values of diets with different fat supplements when fed to lactating dairy cows. J. Dairy Sci. 87:1446-1454.

Weld, K., and L. E. Armentano. 2016. Milk fat secretion in lactating dairy cattle is influenced by soybean particle size and fatty acid profile. J. Dairy Sci. 99:337. (Abstract).

White, T. W., R. B. Grainger, F. H. Baker, and J. W. Stroud. 1958 Effect of supplemental fat on digestion and the ruminal calcium requirement of sheep. J. Anim. Sci. 17:797-803.

Zinn, R. A. 1989. Influence of level and source of dietary fat on its comparative feeding value in finishing diets for feedlot steers: Metabolism. J. Anim. Sci. 67:1038-1049. 